\section{TABLE III.}

\begin{tabular}{|c|c|c|}
\hline \multirow{2}{*}{ Source. } & \multicolumn{2}{|c|}{ Appearance after three weeks' contact with } \\
\hline & Lead Foil. & Lead Pipe. \\
\hline Piethorn ... & Much Greyish Deposit & Slight Greyish \\
\hline Hanging Lees & $\begin{array}{l}\text { Greyish Deposit, with } \\
\text { sliglt glistening ap- } \\
\text { pearance }\end{array}$ & $\begin{array}{l}\text { Greyish Deposit, } \\
\text { with slight glisten- } \\
\text { ing appearance. }\end{array}$ \\
\hline New Year's Bridge & Grey Deposit & $\begin{array}{l}\text { Grey Deposit and } \\
\text { much brown sus- } \\
\text { pended matter. }\end{array}$ \\
\hline Castleshaw & $\mid \begin{array}{ccc}\text { Slight } & \text { Tarnishing of } \\
\text { metal } & \ldots & \cdots \\
& & \end{array}$ & $\begin{array}{l}\text { Yellowish white } \\
\text { deposit, with glis* } \\
\text { tening particles. }\end{array}$ \\
\hline Strinesdale & $\begin{array}{l}\text { Greyish Yellow De- } \\
\text { posit, with slight } \\
\text { glistening particles, } \\
\text { easily derached. }\end{array}$ & $\begin{array}{l}\text { Same as foil, but } \\
\text { m u ch more } \\
\text { marked. }\end{array}$ \\
\hline
\end{tabular}

Although the physical appearances noted above point to the action on lead pipe, which is not pure lead, being greater than on lead foil (pure), chemical analysis did not confirm it, as in each instance only a trace of lead went into solution, and a comparison of the amount was almost an impossibility.

The glistening particles noticed in the case of the water from Strinesdale, and in a less degree in that from Castleshaw, were separated and allowed to dry by contact with the air, and were afterwards treated with a further portion of water from the same reservoir, allowed to remain undisturbed for a few days, and then analysed. Although after the first experiment only a trace of lead was found, this further experiment of allowing the deposit to dry and oxidise resulted in a tenth of a grain of lead per gallon being dissolved.

As was to be expected, it was found that the more acid waters had the greater action on lead.

A further experiment was tried with the Strinesdale water. To a measured portion of the water exactly the same quantity of sodium hydrate solution was added as was found necessary for neutralization when phenolpthallein was used as an indicator, and then exactly similar experiments to those above described, on lead foil and pipe, were carried out, but with absolutely negative results.

From this experiment it would, therefore, appear that the action of the water on lead is due to the acid and the acid only, and this is further borne out by the fact previously noticed, that the more acid waters were much more active in attacking lead.

Another experiment was tried with excess of the sodium hydrate solution, when a most energetic action on the lead foil and pipe was found to take place.

It having come to my knowledge that a large amount of so-called "tin-lined" lead pipe was used in putting in water service pipes, I obtained a portion. This pipe is supposed to be washed with tin in a molten cendition on its inner surface, and it has a whiter and brighter appearance than ordinary lead pipe.

Experiments carried out with this pipe showed conclusively, however, that it is absolutely valueless in preventing the action of the water on. the lead pipe, for there was no difference in any. way between the action of the water on this pipe and the ordinary lead pipe. These experiments were made with the Strinesdale water, as being the most active.

Similar experiments were made with block tinlined lead pipe, on which a plumber had made an ordinary wiped joint, and traces of lead were found in the water, but the quantity was much less than with ordinary lead piping. This pipe consists of a tin pipe, about one-eighth of an inch in thickness, placed within lead piping. It is much more expensive than the ordinary pipe, but it has many advantages, as the water, except in the case of wiped joints, cannot come into contact with lead.

In conclusion, it would appear to be advisable, in order to reduce the plumbo-solvent action of the water, to make every effort to get the water off the peaty gathering grounds as quickly as possible, and afterwards delay it by frequent settling tanks, and decanting from reservoir to reservoir. Also at the Strinesdale Reservoir to expose the water to the vitiated atmosphere as little as possible.

The use of a good quality of block tin lined pipe should be insisted upon as far as possible.

\section{A COMPARATIVE STUDY OF A LOCAL DEATH.RATE, AND THE CAUSES OF ITS REDUCTION.}

BY

Matthew A. Adams, F.R.C.S. Eng., M.O.H. Maidstone. THERE has been a most surprising diminution in the death-rate in the country at large, and in our town of Maidstone in particular.

The mean death-rates in England and Wales were: For the 5 years $1870.74,22{ }^{\circ} 0$; for the 26 years $1870-95,20^{\circ} \mathrm{I},=$ a reduction of 8.6 per cent. ; for the year $1895,18 \%,=a$ reduction of $15 \frac{1}{2}$ per cent, and the consequent saving of life in England and Wales for 1895 alone $=85,313$ persons.

Dealing with Maidstone in precisely the same manner, and making the full allowance necessary for the "age and sex constitution" of the Maidstone population, the results are as follows:-

The mean death-rates in Maidstone were : For the 5 years $1870^{-} 74, x^{\circ} 5$; for the 26 years $1870-95$, $16^{\circ} 9,=$ a reduction of 13.3 per cent.; for the $y$ tar $1895,15^{\circ} \mathrm{O}=\mathrm{a}$ reduction of $23^{\circ} \mathrm{I}$ per cent., and a consequent saving of life in Maidstone during 1895 alone $=105$ persons.

Compared with England and Wales, we find Maidstone to stand as follows :-

During the 5 years $1870-74$ Maidstone, with a 
lower rate by 2.5 per thousand, $=\mathrm{II}^{*} 4$ per cent. reduction; the 26 years $1870-95$, with a lower rate by $3^{\circ} 2$ per thousand, $=15^{\circ} 9$ per cent. reduction ; and in the year 1895 , with a lower rate by 3.7 per thousand, $=20$ per cent. reduction upon England and Wales.

Thus at the commencement of the period under review, Maidstone, with a mortality of $\mathrm{II}^{\circ} 4$ per cent. below the average mortality of England and Wales, in the course of the 26 years the Maidstone rate has been still further reduced to 20 per cent. below. So far the facts and figures are comparatively simple, but to gain an insight into their deeper significance it is necessary they should be extended. When this is done two fresh facts are discovered. First we find that the reduction in the death-rates is not spread equally over the whole year; and secondly, we observe that as between England and Wales on the one hand, and Maidstone on the other, the time incidence as regards the season of the year when the greatest reduction takes place varies. Breaking up the year's records into four quarters, we find that as regards England and Wales, the reduction takes place mainly during the second and fourth quarters; during the first there is no reduction, and, which is very important, there is only a small reduction during the third quarter. On the other hand, as respects Maidstone, we not only find a reduction in all but the fourth quarter, larger than in the case of England and Wales, but we also find that the main reduction took place during the second and third quarters.

The third quarter of the year was not always so healthful for Maidstone.

Taking the period of 26 years, we find that the difference between England as a whole and Maidstone at the beginning was only $\frac{1}{2}$ per cent., and at the ending was $27^{*} 6$ per cent. in favour of Maid. stone, or a gain of no less than 26.6 per cent. As will be seen in the sequel, there is reason to consider the lowness of the death-rate for the third quarter to be the very touchstone of sanitary prosperity.

Our next business is to interpret, as far as may be, these astonishing changes. Speaking broadly, the cause of a high death-rate is Dirt. Clean air, clean soil, clean water, clean food, these are the main things that keep a death-rate low. It goes without saying that country districts are and ought to be more salubrious than town districts, for the reason that country people for the most part have cleaner air to breathe and more of it, cleaner soil to dwell upon and more of it, than town's folk, but although it is usually so, it is not so everywhere, or at all times; some country places, by neglect of sanitary measures, are made most unwholesome; in point of fact, many villages at the present day are, and five-and-twenty years ago even large towns the size of Maidstone were, in a most benighted condition in all that relates to sanitary affairs. It was not until after the Public Health Act of 1875 became law that systematic efforts at sanitation came in vogue; since then, through such efforts, Maidstone has benefitted immensely, and has been raised from a position tending towards the condition of an unhealthy town district to that of a conspicuously healthy country district; and this change has chiefly manifested itself during the second and third quarters, which comprise the warmer months of the year.

This distinction between town and country is well worth looking into, and by what immediately follows it will be seen still more clearly, first how strongly old Maidstone had developed town characteristics, and secondly how thoroughly modern Maidstone has been restored to country attributes.

Of the thirty millions of people that inhabit England and Wales, twenty millions live in town districts and ten millions in country districts. In Table $\mathrm{E}$ these people are broken up into their respective sections for the purpose of exhibiting the points to which $I$ have just referred. This table gives a ten years' average, $1885-94:-1$, of England and Wales; 2 , of town districts; 3 , of couniry districts ; 4. of five years' average for old Maidstone, $1870-74$; and 5 , modern Maidstone during 1895 .

\begin{tabular}{|c|c|c|c|c|c|}
\hline $\mathbf{E}$ & \multicolumn{5}{|c|}{$\begin{array}{l}\text { DEATH RATES.-Comparison } \\
\text { between Town and Country } \\
\text { Districts. }\end{array}$} \\
\hline $\begin{array}{c}\text { IO YEARS AVERAGE, } \\
1885.94\end{array}$ & I. & II. & III. & IV. & Year. \\
\hline $\begin{array}{l}\text { I England and Wales- } \\
\text { Population } \\
30,394,087\end{array}$ & $21^{\circ} 7$ & 18.5 & $16 \cdot 7$ & $18 \cdot 6$ & 189 \\
\hline $\begin{array}{c}2 \text { Town Districts- } \\
\text { Population } \\
20,550,953\end{array}$ & $22 \div 3$ & $19^{\circ} 2$ & $17^{\circ} 9$ & 198 & 19.8 \\
\hline $\begin{array}{c}3 \text { Country Districts- } \\
\text { Population } \\
9.843,125 . \\
\end{array}$ & 20.8 & 1733 & 14.5 & 167 & $17: 3$ \\
\hline $\begin{array}{c}4 \text { Old Maidstone, } \\
1870-74 .\end{array}$ & $2 x \cdot 5$ & 17.9 & $20^{\prime} 6$ & $18^{\circ} 0$ & $19 * 5$ \\
\hline $\begin{array}{c}5 \text { Modern Maidstone, } \\
\text { 1895, corrected. }\end{array}$ & 19.4 & 12.2 & 12.6 & 15.6 & $15^{\circ}$ \\
\hline $\begin{array}{l}\text { Saving of Life in per } \\
\text { cent. in Modern } \\
\text { Maidstone. }\end{array}$ & 9.8 & $31 \times 7$ & $38 \cdot 8$ & $13^{\circ} \mathrm{O}$ & $23^{+} I$ \\
\hline
\end{tabular}

With these figures before us, it is impossible to escape from the conclusion that whereas Maidstone twenty-five years ago exhibited the qualities of an unhealthy town district, now, notwithstanding the increase of her population, presents the characteristics of a healthy country district to a most remarkable degree.

As to the modus operandi of this change.

The explanation is simple and satisfactory: in very large measure it is to be found in the difterence between the sani ary condition of modern as compared with old Maidstone, and the effect warmth 
has upon the fermentation processes in the soil. To some people the very simplicity of this answer may be an obstacle in the way of its acceptance. Here and there an open dust bin, a choked house drain, or a dirty pig-stye, is so much a matter of course, from the popular point of view, that no particular importance is attached to it; yet attention to, or neglect of, these apparently trivial matters makes all the difference between wholesome or unwholesome $\mathrm{t}$ nvironm $\mathrm{nt}$ - this in turn determines the balance betwern health and disease, and often betwixt life and death.

Unsanitary agents such as we are dealing with work their effect by depressing vitality, making the strong less strong and the weak more weak, so that in any given case it is merely a question of what reserve of vitality there may be, whether the person is or is not able successfully to contend against the depression wrought by the unsanitary agent; if not, then invasion by disease or destruction by death ensues, and of course in a large population like our own there are, we may be sure, some of all sorts-men, women, and children-some sick, some sound, some strong, some weak; and we may be also sure that whatever the present strength of any one individual in particular may be, the time must come sooner or later, to each and every one in turn, to hold existence on a precarious tenure, for besides the frailty of infancy and old age, which even under the most favourable circumstances all must face, there are many in the prime of life who have to run the gauntlet of crises, so that there is never lack of scope for the fatal operation of insanitary agents.

If it shall appear that I have given too exclusive prominence to measures relating to the cleansing of the soil and the removal of the effete products of social life, it has not been with a wish to ignore other important considerations-for instance, the maintenance of the purity of food and water, the control of contagion, and the still more hurtful, because more widely prevailing evil, overcrowding. All these and other things have contributed their share in the general result, but on the present occasion we are less concerned in the discussion of the action of sanitation as a whole upon the reduction of the mortalty as we are in the search for the explanation of the special reduction that we have found to occur at certain times of the year under favourable circumstances.

Five-and-twenty years ago no attempt was made to preserve the soil from pollution; privy middens, cesspools, filthy accumulations of house refuse, "sewers of deposit," untended roads and pavements, neglected courts and alleys, abounded everywhere. No wonder that disease-producing and death-dealing organisms flourished, and that the death-rate during the summer quarter was nearly 40 per cent. more than it is now. As we well know, a complete change in all these things has taken place; well drained, well scavenged, well looked after in every respect, modern Maidstone has responded bounteously to the efforts that have been put forth for her redemption.

\section{THE STOCKPORT NEW OUTFALL WORKS AND THE GENERAL QUESTION OF TREATMENT OF SEWAGE.}

BY

\author{
Chas. Porter, M.D., M.O.H., Stockport.*
}

THE sewage and rainfall requiring to be dealt with in the borough are at present discharged direct into the river within the borough from about 30 main-outlet sewers and watercourses. To intercept this sewage and surface-water, very extensive works are being carried out under the supervision of Mr. A. M. Fowler, M.I.C.E., at a cost of over $\mathcal{E}_{100,000}$. The principal feature of the engineer's scheme is the provision of five main intercepting sewers.

At the Outfall Works, the sewage will be pumped I 7 feet 6 inches into tanks, there treated chemically, and then discharged intermittently upon underdrained and levelled filter beds, through which the effluent thus purified will pass into the river. The Corporation possess 95 acres of land at Heathside Farm, and it is proposed to appropriate by degrees 63 acres for sewage purification. The engineer states that it is well adapted for this purpose, being composed of sharp gravel and sand.

Mr. Fowler has made provision in the outfall sewers for the sewage from upwards of 140,000 peopie, and at the Outfall Works, which can at any time be extended, for dealing with the sewage of 107,400 persons, the figures at which he estimates the population $3 \circ$ years hence.

These works are now nearly completed, with the exception of the necessary preparation of filter beds and outfall land over which the treated sewage will flow.

Lime will probably be employed as a precipitant, but the exact details of chemical treatment have not yet been finally decided upon. This matter will require most careful consideration if we are to escape the troubles and mistakes in this respect of other large manufacturing towns, especially in regard to money wasted on the use of "patent" precipitants and filtering media, all of which are very costly and more or less inefficient in practice.

With regard to the employment of lime as a precipitant, the tendency undoubtedly is to limit its use to as small a quantity as may be, firstly, because, as has been shown by Mr. Dibdin, the chemist of the London Cuunty Council, an excess of lime dissolves the suspended organic matter of the sewage, greatly adding to the work of filtration; secondly, because the quantity of sludge is proportionately reduced; and thirdly, because an alkaline

\footnotetext{
* From Dr. Porter's Annual Report, 1895.
} 